\title{
Core/Triple Shell Precipitates in Al-Er-Sc-Zr-(V,Nb,Ta) Alloys
}

\author{
Keith E. Knipling ${ }^{1}$ \\ 1. U. S. Naval Research Laboratory, Multifunctional Materials Branch, Washington, DC
}

Al-Sc alloys are strengthened by nanoscale $\mathrm{Al}_{3} \mathrm{Sc}$ precipitates [1]. By alloying with faster-diffusing Er and slower-diffusing $\mathrm{Zr}$ additions, complex core/double-shell precipitates are formed, consisting of an Er-enriched core surrounded by a Sc- and Zr-enriched shell [2]. The Er-enriched core enhances strength while the Zr-enriched outer shell improves thermal stability. The present study seeks ultimate strength and coarsening resistance by alloying Al-Er-Sc-Zr alloys with Group 5 additions $(\mathrm{M}=\mathrm{V}, \mathrm{Nb}, \mathrm{Ta})$, which are expected to be slower diffusers than $\mathrm{Zr}$ [3]. By sequential nucleation of the constituent solutes we have engineered complex core/triple shell $\mathrm{Al}_{3}(\mathrm{Er}, \mathrm{Sc}, \mathrm{Zr}, \mathrm{M})$ coarsening-resistant precipitates.

This study investigates the nanostructures and compositions of $\mathrm{Al}_{3}(\mathrm{Er}, \mathrm{Sc}, \mathrm{Zr}, \mathrm{M})$ precipitates formed during isochronal aging of dilute Al-0.004Er-0.056Sc-0.060Zr-0.060(V/Nb/Ta) (at.\%) alloys made by arc melting. The alloys also contained $0.016-0.019$ at.\% Si, which decreases the Sc migration energy in $\mathrm{Al}$ thereby accelerating the precipitation kinetics [4]. Prior to aging, the alloys were first homogenized for $72 \mathrm{~h}$ at $640{ }^{\circ} \mathrm{C}$ to eliminate microsegregation of solutes after casting. The alloys were then aged isochronally in $25{ }^{\circ} \mathrm{C}$ increments each lasting $3 \mathrm{~h}$, from $200-600{ }^{\circ} \mathrm{C}$. The specimens were waterquenched between each aging increment and precipitation was monitored by Vickers microhardness and electrical conductivity measurements using a LECO AMH43 automatic hardness tester (200 g load) and a General Electric AutoSigma 3000 electrical conductivity meter, respectively. The microstructures responsible for strengthening were investigated by atom-probe tomography (APT) with a Cameca LEAP 4000x Si. Specimens for APT were prepared using standard lift-out and focused ion beam (FIB) milling procedures [5] in an FEI Nova 600 NanoLab DualBeam ${ }^{\mathrm{TM}}$ SEM/FIB.

Figure 1 displays the evolution of microhardness and electrical conductivity with temperature for the AlEr-Sc-Zr and Al-Er-Sc-Zr-V alloys. Between 200 and $225^{\circ} \mathrm{C}$ there is a small increase in microhardness and electrical conductivity, which is attributed to precipitation of $\mathrm{Al}_{3} \mathrm{Er}$. The largest strength increase, $\sim 220 \mathrm{MPa}$, occurs between 250 and $300{ }^{\circ} \mathrm{C}$, which is attributed to precipitation of Sc onto the $\mathrm{Al}_{3} \mathrm{Er}$ precipitates. This is followed by a secondary increase in microhardness and electrical conductivity between 350 and $400{ }^{\circ} \mathrm{C}$, which is attributed to precipitation of $\mathrm{Zr}$ onto the $\mathrm{Al}_{3}(\mathrm{Er}, \mathrm{Sc})$ precipitates. The alloys reach peak microhardness at 400 or $425^{\circ} \mathrm{C}$ and peak electrical conductivity, corresponding to a maximum volume fraction of precipitates, at $425{ }^{\circ} \mathrm{C}$. Above this temperature there is significant overaging, marked by a continuous decrease in strength. The microhardness and electrical conductivity results in Figure 1 indicate no obvious benefits from the addition of $\mathrm{V}$.

Figure 2 displays an atom probe reconstruction of the Al-Er-Sc-Zr-V alloy isochronally aged to $425{ }^{\circ} \mathrm{C}$ (peak strength). The core/triple-shell nanostructure of the $\mathrm{Al}_{3}(\mathrm{Er}, \mathrm{Sc}, \mathrm{Zr}, \mathrm{V})$ precipitates is seen in the reconstructions and also quantified in the proximity histogram [5]. While some of it partitions to the precipitates, most of the $\mathrm{V}$ remains in solid solution due to the slow diffusion kinetics of $\mathrm{V}$ in $\mathrm{Al}$.

This study will present the complete precipitate evolution of $\mathrm{Al}_{3}(\mathrm{Er}, \mathrm{Sc}, \mathrm{Zr})$ precipitates during isochronal aging of Al-0.004Er-0.056Sc-0.060Zr (at.\%) from $200-600{ }^{\circ} \mathrm{C}$, and also discuss the effects of $\mathrm{V}, \mathrm{Nb}$, and Ta to this alloy. 
References:

[1] EA Marquis and DN Seidman, Acta Materialia 49 (2001), p. 1909.

[2] C Booth-Morrison, DC Dunand and DN Seidman, Acta Materialia 59 (2011), p. 7029.

[3] KE Knipling, DC Dunand and DN Seidman, International Journal of Materials Research 97 (2006), p. 246.

[4] C Booth-Morrison et al, Acta Materialia 60 (2012), p. 4740.

[5] K Thompson et al, Ultramicroscopy 107 (2007), p. 131.

[6] OC Hellman et al, Microscopy and Microanalysis 6 (2000), p. 437.

[7] This work was funded by the Naval Research Laboratory under the auspices of the Office of Naval Research. We thank Prof. Paul Saunders (Michigan Technological University) and Profs. David Dunand and David Seidman (Northwestern University) for providing the master alloys used.
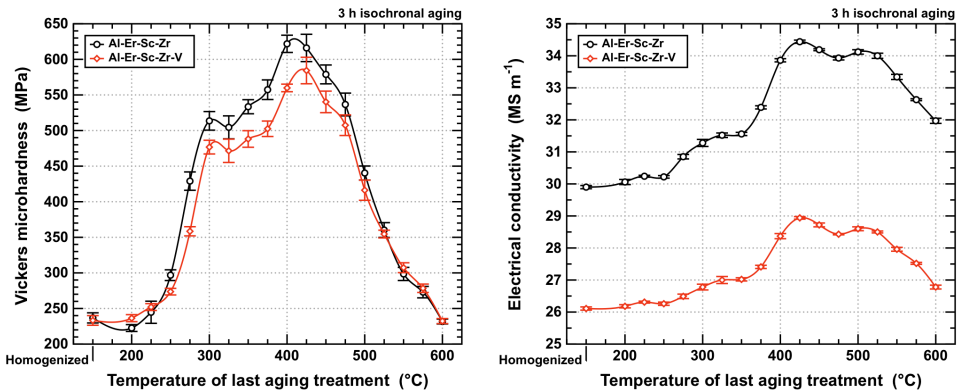

Figure 1. Vickers microhardness and electrical conductivity evolution during isochronal aging ( $3 \mathrm{~h}$ at each temperature) of the Al-Er-Sc-Zr and Al-Er-Sc-Zr-V alloys.

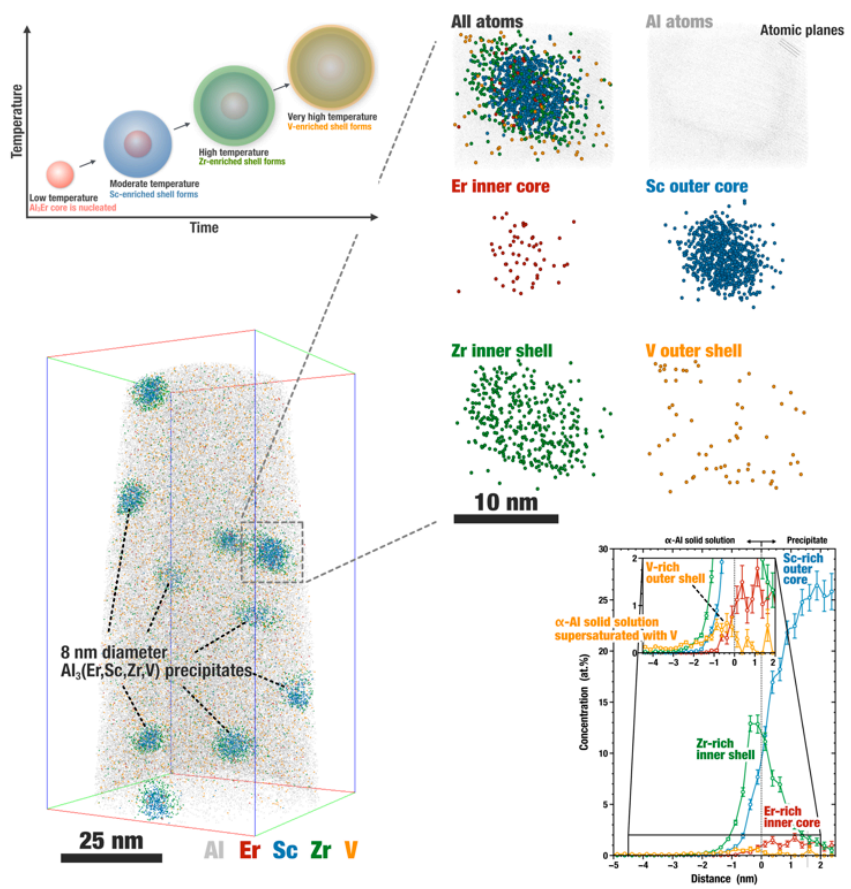

Figure 2. Atom probe reconstruction of the Al-Er-Sc-Zr-V alloy isochronally aged to $425{ }^{\circ} \mathrm{C}$. The core/triple-shell nanostructure of the $\mathrm{Al}_{3}(\mathrm{Er}, \mathrm{Sc}, \mathrm{Zr}, \mathrm{V})$ precipitates is seen in the three-dimensional reconstructions and also quantified in the proximity histogram. 